\title{
A Comparison of Subacromial Bursae Block, Suprascapular Nerve Block and Interscalene Brachial Plexus Block after Arthroscopic Shoulder Surgery
}

\author{
J. Ovesen ${ }^{1}$, T. Falstie-Jensen ${ }^{2}$, C. Christensen ${ }^{3}$ \\ ${ }^{1}$ Shoulder and Elbow Clinic, Aarhus University Hospital, Aarhus, Denmark \\ ${ }^{2}$ Shoulder and Elbow Clinic, Randers Hospital, Randers, Denmark \\ ${ }^{3}$ Department of Anesthesiology, Randers Hospital, Randers, Denmark \\ Email: jannoves@rm.dk
}

Received 10 May 2014; revised 17 June 2014; accepted 1 July 2014

Copyright (C) 2014 by authors and Scientific Research Publishing Inc.

This work is licensed under the Creative Commons Attribution International License (CC BY).

http://creativecommons.org/licenses/by/4.0/

c) (i) Open Access

\section{Abstract}

Background: The aim of this study was to compare the analgesic efficacy of subacromial bursae block (LA), suprascapular nerve block (SSB), and interscalene brachial plexus block (ISB) after arthroscopic shoulder surgery. Methods: 91 patients scheduled to undergo an arthroscopic shoulder acromioplasty under GA in an outpatient setting were included. The patients were prospectively randomized into 4 groups: 1) interscalene brachial plexus block, 2) suprascapular nerve block, 3) subacromial bursae block, 4) control group for comparison. Pain scores (VAS), supplemental analgesia, and side effects were recorded in the recoveryroom, 4 hours and 24 hours after surgery. Results: Group ISB had significantly lower pain scores at rest in the postanesthesia care unit than the SSB group $(p=0.037)$ and the control group $(p=0.0313)$. The same results were seen 4 hours follow-up. The LA group had significantly lower pain scores at rest in the postanesthesia care unit than the control group $(p=0.046)$ and after 4 hours follow-up significantly lower pain scores than both the SSB group $(p=0.021)$ and the control group $(p=0.037)$. After 24 hours, there were no differences between the two groups. Conclusion: In this prospective, randomized, blinded study we demonstrated that a single-dose interscalene brachial plexus block (ISB) and a subacromial bursae block (LA) are equal and the most efficient analgesic techniques after arthroscopic shoulder acromioplasty. LA is less expensive, faster and with fewer complications than ISB and therefore we suggest subacromial bursae block is an effective, safe and easy way of postoperative pain reduction after arthroscopic acromioplasty. Level of evidence: Level I. Treatment study. 


\section{Keywords}

\section{Shoulder Surgery, Pain Relief, Interscalene Block, Subacromial Bursae Block, Suprascapular Block}

\section{Introduction}

Advances in arthroscopic shoulder technology allow many surgical shoulder procedures that once required hospitalization to be performed on a same-day basis. However, arthroscopic procedures are often associated with severe postoperative pain [1]. Therefore, effective pain relief in an outpatient setting is mandatory. Supplementing general anesthesia (GA) with a regional nerve block have shown to improve the quality of postoperative pain relief and eases postoperative recovery [2]-[4]. The objective of this study was to compare the efficacy of interscalene brachial plexus block (ISB), subacromial bursa block (LA), and suprascapular nerve block (SSB) after arthroscopic subacromial decompression in an outpatient setting. Our hypothesis was that subacromial bursae block could be as effective as different nerveblock after arthroscopic decompression of the shoulder.

\section{Materials and Methods}

Institutional approval was obtained to conduct this blinded, prospective, randomized clinical trial. 100 patients scheduled to undergo an outpatient arthroscopic shoulder acromioplasty under GA were primary included in this study. The surgical indications for surgery were pain for more than 6 months with no effects of physiotherapy, work restrictions or subacromial steroid block. If the operation changed from acromioplasty to cuff repair, bicepstenodesis or combined with ac-resection, the patients were excluded. Patients were also excluded if they had coagulation abnormality, age $<20$ or $>75 \mathrm{yr}$, weight $<50$ or $>110 \mathrm{~kg}$, or inability to read and understand information and pain scales. Patients were randomly divided into 4 groups of 25 by using a random number table and a sealed envelope sequence concealed until after the enrolment of the subject.

\subsection{The Blocks Were Performed after the Induction of GA}

\subsubsection{Interscalene Brachial Plexus Block (ISB)}

The block was performed by following Winnie's landmarks. A stimuplex needle connected to a peripheral nervestimulator was introduced into the plexus sheath. Its position was judged adequate when muscles distal to the deltoid were stimulated with a threshold stimulation $<0.3 \mathrm{~mA}$. Then $30 \mathrm{ml}$ of ropivacaine $(7.5 \mathrm{mg} / \mathrm{ml})$ was injected.

\subsubsection{Suprascapular Nerve Block (SSB)}

A $5 \mathrm{~cm}$, 21 gauge IM needle was introduced $1 \mathrm{~cm}$ cephalad to the middle of the spine of the scapulae and advanced parallel to the blade until the bony floor of the fossa supraspinatus was reached. Then $20 \mathrm{ml}$ of bupivicaine $(5 \mathrm{mg} / \mathrm{ml})$ was installed.

\subsubsection{Subacromial Bursae Block (LA)}

Postoperatively the surgeon injected $10 \mathrm{ml}$ bupivacaine $(5 \mathrm{mg} / \mathrm{ml})$ and $5 \mathrm{ml}$ morphine $(0.4 \mathrm{mg} / \mathrm{ml})$ into the subacromiale space.

\subsubsection{Control Group}

This group had no block performed.

In all patients, GA was induced with propofol and remifentanyl. The trachea was intubated/larynxmask and controlled ventilation started. They were all given dimethylaminphren (DHB) $0.625 \mathrm{mg}$ i.v. to avoid nausea and $0.1 \mathrm{mg}$ Fentanyl 10 - 15 min before end of surgery.

Pain at rest (Visual Analog Scale) ranging from $0=$ no pain to $10=$ worst imaginable pain were assessed subjectively in the postanesthesia care unit and respectively 4 hours after surgery with help from a nurse. After 24 hours the VAS score was assessed by the patient at home. Supplemental postoperative analgesia was standardized. All patients had $1 \mathrm{~g}$ of paracetamol $\times 4$ and $600 \mathrm{mg}$ of Ibrufen $\times 3$ daily. If VAS was $>3$, patients received 3 - 5 mg nicomorphinhydrochlorid iv, followed by $5 \mathrm{mg}$ ketomebidon + dimethylaminphren. Supplemental an- 
algesia, side effects and VAS were recorded 24 hours after surgery for all patients.

\subsection{Statistic}

Values are reported as mean \pm standard deviation (SD). Paired t-test was used to determine the statistical significance. The level of significance was set at $\mathrm{p}<0.05$.

\subsection{Ethics}

We obtained oral and written informed patient consent to perform the study. The study is approved by the Regional Scientific Ethical Committee for Denmark.

\section{Results}

During the study period (2007-2011), 100 patients undergoing ambulatory shoulder surgery were primary included. 9 patients were excluded; 6 had a cuff repair and one a bicepstenodesis and 2 patients did not returned their VAS score. Population data were comparable in all groups as demonstrated in Table 1.

\subsection{VAS Scores}

VAS scores at rest immediately after arrival to the postanesthesia care unit, after 4 hours and after 24 hours are presented in Table 2. Group ISB had significantly lower pain scores at rest in the postanesthesia care unit than the SSB group $(p=0.037)$ and the control group $(p=0.0313)$. The same results were found after 4 hours follow-up; the ISB group had significantly lower VAS score than the SSB group $(p=0.026)$ and the control group ( $p=0.041$ ), but not compared to the LA group. Furthermore the LA group had significantly lower pain scores at rest in the postanesthesia care unit than the control group $(\mathrm{p}=0.046)$ and after 4 hours follow-up significantly lower pain scores than both the SSB group $(p=0.021)$ and the control group $(p=0.037)$. After 24 hours there were no differences between the four groups.

\subsection{Morphine Supplemental and Side Effects}

Comparing the ISB group with the other groups no significantly less morphine was administrated during the first 24 hours after surgery. Side effects in the four groups are presented in Table 3. No permanent complications were reported in our study.

\section{Discussion}

This prospective, randomized, blinded study demonstrated that a single-dose interscalene brachial plexus block (ISB) and a subacromial bursa block (LA) are equal and the most efficient analgesic techniques after arthro-

Table 1. Population data in the four grops.

\begin{tabular}{ccccc}
\hline & Group ISB & Group SSB & Group LA & 22 \\
\hline No. of patients & 22 & 23 & 54.77 & 48.79 \\
Mean age (years) & 48.95 & 48.70 & $7 / 15$ & $10 / 14$ \\
Sex (m/f) & $11 / 11$ & $7 / 16$ & 7 Control \\
\hline
\end{tabular}

ISB = interscalene block; SSB = suprascapular block; LA = local analgesia.

Table 2. Pain scores and supplemental morphine in the four groups.

\begin{tabular}{|c|c|c|c|c|c|}
\hline & Group ISB & Group SSB & Group LA & Control & p-value \\
\hline VAS PCU & $0.09 \pm 0.43^{\mathrm{a}, \mathrm{c}}$ & $0.96 \pm 1.73$ & $0.318 \pm 0.57^{\mathrm{c}}$ & $1.30 \pm 2.2$ & $<0.037$ \\
\hline VAS 4 hours & $0.68 \pm 1.25^{\mathrm{a}, \mathrm{c}}$ & $1.70 \pm 1.66$ & $0.727 \pm 0.88^{\mathrm{a}, \mathrm{c}}$ & $1.5 \pm 1.35$ & $<0.036$ \\
\hline VAS 24 hours & $3.09 \pm 2.49$ & $3.21 \pm 2.51$ & $2.45 \pm 2.34$ & $2.45 \pm 2.33$ & $>0.388$ \\
\hline Total Morphine (mg/24 h) & $2.0 \pm 4.70$ & $3.65 \pm 7.71$ & $4.14 \pm 8.54$ & $5.67 \pm 10.46$ & $>0.573$ \\
\hline
\end{tabular}

VAS = visual analog scale at rest; ISB = interscalene block; SSB = suprascapular block; LA = local analgesia; PCU = postanaesthesia care unit; ${ }^{\text {a Sig- }}$

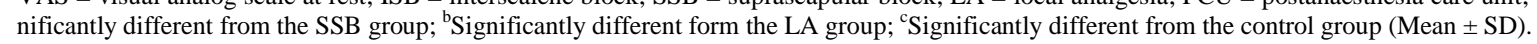


Table 3. Side effects in the four groups.

\begin{tabular}{ccccc}
\hline & $\begin{array}{c}\text { ISB group } \\
(\mathrm{n}=22)\end{array}$ & $\begin{array}{c}\text { SSB group } \\
(\mathrm{n}=23)\end{array}$ & $\begin{array}{c}\text { LA group } \\
(\mathrm{n}=22)\end{array}$ & $\begin{array}{c}\text { Control group } \\
(\mathrm{n}=24)\end{array}$ \\
\hline Nausea/Vomiting & 1 & 1 & 3 & 2 \\
"Dead arm" & 5 & 1 & 1 & 0 \\
Local tenderness & 4 & 3 & 1 & 0 \\
\hline
\end{tabular}

ISB = interscalene block; SSB = suprascapular block; LA = local analgesia.

scopic shoulder acromioplasty. ISB and LA provided the lowest pain scores (VAS) at rest in the postanesthesia care unit and after 4 hours.

Because the supracapularis nerve innervates the major part up of the posterior shoulder joint, the acromioclavicular joint and the subacromial space, it is reasonable to assume that SSB would be valuable to treat shoulder pain after surgery. But as we demonstrated in our study, it is less effective than a single-dose ISB and after 4 hours also significant less effective than a subacromial bursa block. Furthermore, it did not decrease the need for morphine during the postoperative period, similar to further reported results [5].

Singely and coauthors demonstrated no effects of intraarticular local anesthetic after arthroscopic acromioplasty, even though the injection was performed after skin closure, which is different from our results. In the postanaesthesia care unit, 4 hours and 24 hours after surgery, we did not find any significantly differences between group ISB and group LA. The main reason could be that we injected the local analgesia in the subacromial space (subacromial bursae block), where the main surgery is performed and not intraarticulary as Singelyn et al. [4].

Several studies have compared the benefit of infusion pump to the subacromial space compared to a single block and concluded the continuous subacromial infusion to be ineffective [6]-[8]. Some studies have reported continuous interscalene analgesia to be superior to a single interscalene block [9] [10]. We decided not to use continuous infusion because of the infection risk and because of the low VAS score after 24 hours. Nisar and coauthors demonstrated like in our study, that there were no significantly differences between ISB and subacromial bursae block regarding to pain scores in the first 12 hours postoperatively after arthroscopic subacromial decompression in patients with an intact rotator cuff [11].

The interscalene block and the subacromial bursae block provides effective pain relief immediately postoperatively and after 4 hours, but these blocks only lasts for 12 to 16 hours and after 24 hours our study showed no differences in pain relief in the four groups. This is comparable to other studies [3]. Previously studies have demonstrated a reduction in analgesic requirements in the postanesthesia care unit and after 4 hours after interscalene block [1] [3] [9] [10] [12]-[17]. In our study we demonstrated a decreased use of morphine in the ISB and LA group, but it was not significant.

Application of block is an invasive procedure that requires anesthesiologists trained in the technique. Both interscalene and suprascapular blocks have been associated with multiple complications, including pneumothorax, phrenic nerve injuries, anesthetic toxicity leading to cardiac arrest, seizures and permanent nerve injury [2] [8] [18]-[21]. One of the major complications after interscalene block has been neurapraxis [13] In our study we did not find this complication, one reason could be that we as a common practice use an arm holder in the beachchair position to prevent traction. Another approach to reduce complications associated with blocks has been the introduction and increasing popularity of ultrasound guidance, which is now introduced in many hospitals [22]-[24].

The study has some limitations. The amount of analgesia given as a subacromial bursae block could vary from one to another, because some of the liquid might leak out through the portals. Another limitation is that the bursae block was given by the surgeob to what he/she believed was the subacromial space and therefore theoretical could be injected to the supraspinatus muscle instead.

\section{Conclusion}

In this prospective, randomized, blinded study we demonstrated that a single-dose interscalene brachial plexus block (ISB) and a subacromial bursae block (LA) are equal and the most efficient analgesic techniques after arthroscopic shoulder acromioplasty. LA is less expensive, faster and with fewer complications than ISB and therefore we suggest subacromial bursae block is an effective, safe and easy way of postoperative pain reduction 
after arthroscopic acromioplasty.

\section{References}

[1] Watson, W., Chung, F., Chan, V.W. and Mcgillon, M. (2004) Pain Management Following Discharge after Ambulatory Same-Day Surgery. Journal of Nursing Management, 12, 153-161. http://dx.doi.org/10.1111/j.1365-2834.2004.00470.X

[2] Bishop, J.Y., Spraque, M., Gelber, J., Krol, M., Rosenblatt, M.A., Gladstone, J.N. and Flatow, E.L. (2006) Interscalene Regional Anesthesia for Arthroscopic Shoulder Surgery: A Safe and Effective Technique. Journal of Shoulder and Elbow Surgery, 15, 567-570. http://dx.doi.org/10.1016/j.jse.2006.01.009

[3] Bogdanov, A. and Loveland, R. (2005) Is There a Place for Interscalene Block Performed after Induction of General Anaesthesia? European Journal of Anaesthesiology, 22, 107-110. http://dx.doi.org/10.1017/S0265021505000207

[4] Singelyn, F.J., Laurence, L. and Fabre, B. (2004) Pain Relief after Arthroscopic Shoulder Surgery. A Comparison of Intraqarticular Analgesia, Suprascapular Nerve Block, and Interscalene Brachial Plexus Block. Anesthesia \& Analgesia, 99, 589-592. http://dx.doi.org/10.1213/01.ANE.0000125112.83117.49

[5] Oh, J.H., Rhee, K.Y., Kim, S.H., Lee, P.B., Lee, J.W. and Lee, S.J. (2009) Comparison of Analgesic Efficacy between Single Interscalene Block Combined with Continouos Intra-Bursal Infusion of Ropivacaine and Continouos Interscalene Block after Arthroscopic Rotator Cuff Repair. Clinics in Orthopedic Surgery, 1, 48-53. http://dx.doi.org/10.4055/cios.2009.1.1.48

[6] Boss, A.P., Maurer, T., Seiler, S., Aeschbach, A., Hintermann, B. and Strebel, S. (2004) Continous Subacromial Bupivacaine Infusion for Postoperative Analgesia after Open Acroimioplasty and Rotatorcuff Repair: Preliminary Results. Journal of Shoulder and Elbow Surgery, 13, 630-634. http://dx.doi.org/10.1016/j.jse.2004.04.005

[7] Ciccone, W.J., Busey, T.D., Weinstein, D.M., Walden, D.L. and Elias, J.J. (2008) Assessment of Pain Relief Provided by Interscalene Regional Block Ad Infusion Pump after Arthroscopic Shoulder Surgery. Journal of Arthroscopic \& Related Surgery, 24, 14-19.

[8] Nishiyama, T. and Komatsu, K. (2010) Local Anesthetic in Interscalene Block. Clinical Series. Minerva Anestesiologica, 76, 1088-1090.

[9] Fredericson, M.J., Krishnan, S. and Chen, C.Y. (2010) Postoperative Analgesia for Shoulder Surgery. A Critical Appraisal and Review of Current Techniques. Anaesthesia, 65, 608-624. http://dx.doi.org/10.1111/j.1365-2044.2009.06231.x

[10] Fredericson, M.J., Ball, C.M. and Dalgleish, A.J. (2008) Succesful Continouos Interscalen Analgesia for Ambulatory Shoulder Surgery in a Private Practice Setting. Regional Anesthesia and Pain Medicine, 33, 122-128. http://dx.doi.org/10.1097/00115550-200803000-00006

[11] Nisar, A., Morris, M.W., Freeman, J.V., Cort, J.M., Rayner, P.R. and Hahane, S.A. (2008) Subacromial Bursae Block Is an Effective Alternative to Interscalene Block for Postoperative Pain Control after Artroscopic Subacromial Decompression: A Randomized Trial. Journal of Shoulder and Elbow Surgery, 17, 78-84. http://dx.doi.org/10.1016/j.jse.2007.05.014

[12] Borgeat, A. and Ekatodramis, G. (2002) Anaesthesia for Shoulder Surgery. Best Practice \& Research Clinical Anaesthesiology, 16, 211-225. http://dx.doi.org/10.1053/bean.2002.0234

[13] Faryniarz, D., Morelli, C., Coleman, S., Holmes, T., Allen, A., Altchek, D., Cordasco, F., Warren, R.F., Urban, M.K. and Gordon, M.A. (2006) Interscalene Block Anesthesia at an Ambulatory Surgery Center Performing Predominantly Regional Anesthesia: A Prospective Study of One Hundred Thirty-Three Patients Undergoing Shoulder Surgery. Journal of Shoulder and Elbow Surgery, 15, 686-690. http://dx.doi.org/10.1016/j.jse.2006.02.001

[14] Laurila, P.A., Lopponen, A., Kanga-Saarela, T., Flinkkila, T. and Salomaki, T.E. (2002) Interscalene Brachial Plexus Block Is Superior to Subacromial Bursa Block after Arthroscopic Shoulder Surgery. Acta Anaesthesiologica Scandinavica, 46, 1031-1036. http://dx.doi.org/10.1034/j.1399-6576.2002.460818.x

[15] Stiglitz, Y., Gosselin, O., Sedaghatian, J., Sirveaux, F. and Mole, D. (2011) Pain after Shoulder Surgery. A Prospective Study on 231 Cases. Orthopaedics and Traumatology, 97, 260-266.

[16] Wilson, A.T., Nicholson, E., Burton, L. and Wild, C. (2004) Analgesia for One-Day Shoulder Surgery. British Journal of Anaesthesia, 92, 414-415. http://dx.doi.org/10.1093/bja/aeh071

[17] Wurm, W.H., Concepcion, M., Sternlicht, A., Carabuena, J.M., Robelen, G., Goudas, L.C., Strassels, S.A. and Carr, D.B. (2003) Preoperative Interscalene Block for Elective Shoulder Surgery: Loss of Benefit over Early Postoperative Block after Patient Discharge to Home. Anesthesia \& Analgesia, 97, 1620-1626. http://dx.doi.org/10.1213/01.ANE.0000090320.46129.BE

[18] Clendenen, S.R., Robards, C.B., Wang, R.D. and Greengrass, R.A. (2009) Continous Interscalene Block Associated 
with Neck Hematoma and Postoperative Sepsis. Anesthesia-Analgesia, 9.

[19] Cohen, J.M. and Gray, A.T. (2010) Functional Deficit after Intraneural Injection during Interscalene Block. Regional Anesthesia and Pain Medicine, 35, 397-399. http://dx.doi.org/10.1097/AAP.0b013e3181e8a35f

[20] Eroglu, A., Uzunlar, H., Sener, M., Akinturk, Y. and Erciyes, N. (2004) A Clinical Comparison of Equal Concentration and Volume of Ropivacaine and Bupivacain for Interscalene Brachial Plexus Anesthesis and Analgesia in Shoulder Surgery. Regional Anesthesia and Pain Medicine, 29, 539-543. http://dx.doi.org/10.1097/00115550-200411000-00006

[21] Lenters, T.R., Davies, J. and Matsen, F.A. (2007) The Types and Severety of Complications Associated with Interscalene Brachial Plexus Block Anesthesia: Local and National Evidence. Journal of Shoulder and Elbow Surgery, 16, 379-387. http://dx.doi.org/10.1016/j.jse.2006.10.007

[22] Liu, S.S., Zayas, V.M., Gordon, M.A., Beathe, J.C., Maalouf, D.B., Paroli, L., Liguori, G.A., Ortiz, J., Buschiazzo, V., Ngeow, J., Shetty, T. and Ya Deau, J.T. (2009) A Prospective, Randomized, Controlled Trial Comparing Ultrasound versus Nerve Stimulator Guidance for Interscalene Block for Ambulatory Shoulder Surgery for Postoperative Neurological Symptoms. Anesthesia \& Analgesia, 109, 266-271. http://dx.doi.org/10.1213/ane.0b013e3181a3272c

[23] McNaught, A., Shastri, U., Camichael, N., Awad, I.T., Columb, M., Cheung, J., Holtby, R.M. and McCartney, C.J. (2011) Ultrasound Reduces the Minimum Effective Local Anaesthetic Volume Compared with Peripheral Nerve Stimulation for Interscalene Block. British Journal of Anaesthesia, 106, 124-130. http://dx.doi.org/10.1093/bja/aeq306

[24] Spencer, S.L., Victor, M.Z., Gordon, M.A., Maalouf, D.B., Paroli, L., Liguori, G.A., Ortiz, J., Buschiazzo, V., Ngeow, J., Shetty, T. and Ya Deau ,T.Y. (2008) Aprospective, Randomized, Controlled Trial Comparing Ultrasound versus Nervestimulator Guidance for Interscalene Block for Ambulatory Shoulder Surgery for Postoperative Neurological Symptoms. Anesthesia-Analgesia, 8. 
Scientific Research Publishing (SCIRP) is one of the largest Open Access journal publishers. It is currently publishing more than 200 open access, online, peer-reviewed journals covering a wide range of academic disciplines. SCIRP serves the worldwide academic communities and contributes to the progress and application of science with its publication.

Other selected journals from SCIRP are listed as below. Submit your manuscript to us via either submit@scirp.org or Online Submission Portal.
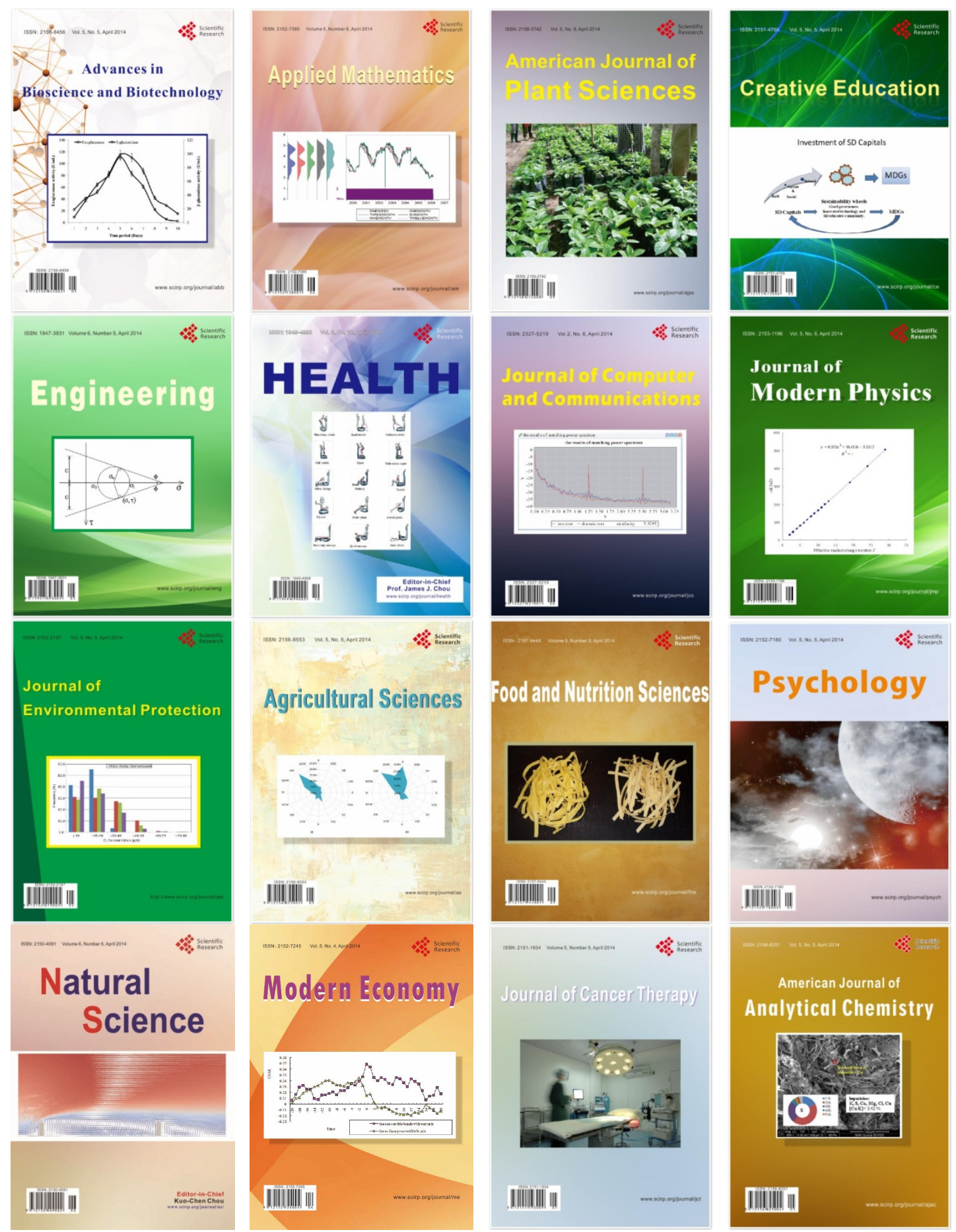